\title{
Editorial
}

\section{TRANSLATIONAL, MULTIDISCIPLINARY AND INTEGRATIVE STUDIES IN NEUROPHYSIOLOGY: REAL NEED OR CONTEMPORARY FASHION IN BRAIN RESEARCH?}

\begin{abstract}
Dragan Hrnčić ${ }^{1}$
${ }^{1}$ University of Belgrade, Faculty of Medicine, Institute of Medical Physiology "Rihard Burian", Laboratory for Neurophysiology, Belgrade, Serbia
\end{abstract}

Correspondence: dragan.hrncic@mfub.bg.ac.rs

Why brain research is important? Do we have strategies to cope with brain diseases? What can we do to facilitate the progress in our understanding of basic and advanced neurophysiology functions responsible for our successful integration in the environmental eco -system? These are just some of the questions that all stakeholders in big arena of brain research share in common. In order to be more understandable for policy makers and the society, neuroscience, neurological and psychiatric research are nowadays frequently referred to as brain research. In the same sense, brain diseases encompass disorders also known as neurological or psychiatric (1)

In many opinions and reports, brain diseases are recognized and labeled as a considerable social and economic burden in Europe and beyond (1). Namely, by having affected 179 million people in 2010 and estimated direct and indirect costs of more than 800 billion euros $(2,3)$, brain diseases are at the forefront of medical and social problems, being recognized as a grand challenge for neuroscientists (1-3). Despite the significant progress in our understanding of how our nervous system functions, we still lack some major answers. On the other hand, patients' everyday needs for health care are continuously increasing and most of the healthcare systems are trying to respond to it in a proper way. In many of brain diseases we still lack adequate treatments. Altogether, unquestionably we need a tremendous research efforts to cope with all open issues related to nervous system functions and dysfunctions. Different study approaches are available. Choice depends on us.
Multidisciplinary collaboration:

let's (net)work together

Era of single - author studies in a broad area of biomedical research has finished decades ago. One discipline studies approach is obsolete also, being overlaid by interdisciplinary approach broadly defined as "a mode of research by teams or individuals that integrates information, data, techniques, tools, perspectives, concepts, and/or theories from two or more disciplines or bodies of specialized knowledge to advance fundamental understanding or to solve problems whose solutions are beyond the scope of a single discipline or area of research practice"(4).

Novel research methods and techniques require extensive education and training. Scientists developed their own rules of study design, research conductance, project financing and management, data collection, interpretation and presentation, as well as results publication and communication with lay public. Ethical issues are strictly monitored. Good practice of responsible conduct of research is causa sine qua non in contemporary scientific work. Evaluation is ongoing process utilizing simple to complex success indicators. All these, and a lot of unmentioned facets, bestow additional stress upon "human resources" in scientific research in all biomedical fields, as well as in brain research field. On the other hand, the ultimate goal of the society is to cope with all threats for human health and life quality. In final instance, society is initiator, financial sponsor and consumer of scientific knowledge produced in machinery of well-managed research lines. The 
Hrnčić D. Translational, multidisciplinary and integrative studies in neurophysiology: real need or contemporary fashion in brain research . MedPodml 2018, 69(3):1-2

only way to achieve these goals in the given circumstances is to cooperate, not just within the own wards and sub disciplines, but in the whole scientific environment. Only a well-established network of multiple scientific layers, educational backgrounds, techniques and methods represented by researchers arising from different disciplines will be sufficient. Therefore, teams of medical practitioners, biomedical scientist in the broadest sense of life sciences, engineers, economists, social scientists etc. are successful teams. Evidently, we need the key element, multidisciplinary collaboration, in order to cope with burden of brain diseases.

\section{Translational studies: from idea to implementation}

If we are going to understand the issue of multidisciplinary approach as a horizontal integration, then our next step is to understand how to integrate vertically. Translational research approach passed a way from nice idea to widely accepted scientific highroad. Translational research could be defined in several ways, but mostly it has been referred to as "research (which) transforms scientific discoveries arising from laboratory, clinical or population studies into new clinical tools and applications that improve human health by reducing disease incidence, morbidity and mortality" (5). Indeed, in brain and biomedical research area in general, we are sometimes unaware of different roles and relations that we can play and have in process of medical practice and sciences. Often, these are split. From clinical perspective, it is important to diagnose and cure already diseased patient. From population based studies we want to gain knowledge on interventions capable to influence the population as a whole. In basic studies, we want to understand mechanisms and find targets for establishing or improving therapeutic armamentaria, or biomarkers that will facilitate early diagnosis. Hence, another definition also fits nicely: "Translational research fosters the multidirectional integration of basic research, patient-oriented research, and population-based research, with the long-term aim of improving the health of the public" (6). If we think on three major pillars of health: sleep, nutrition and physical activity, in general, and particularly in modulation of brain excitability, we can successfully adopt this translational research approach, as discussed elsewhere (7). By integrating benchside, bedside and community studies on brain diseases we will achieve our goals in prevention, diagnosis, and therapies of major brain disorders like epilepsy, Alzheimer's and Parkinson's disease, schizophrenia, anxiety and others that are in accordance with the scope of translational medicine (8). Significance of translational medicine/research has been recognized by major funding bodies in the world, like USA National Institute of Health (NIH) which set it as its priority dedicating a large proportion of funding for these researches (9). We can notice that implementation of translational research is in progress. Tangible results are bound to come in the near future.

\section{References}

1. DiLuca M, Olesen J. The cost of brain diseases: a burden or a challenge? Neuron; 82(6):1205-8.

2. GBD 2015 Neurological Disorders Collaborator Group. Global, regional, and national burden of neurological disorders during 1990-2015: a systematic analysis for the Global Burden of Disease Study 2015. Lancet Neurol 2017; 16: 877-97

3. Olesen J, Gustavsson A, Svensson M, Wittchen HU, Jönsson B; CDBE2010 study group; European Brain Council. The economic cost of brain disorders in Europe. Eur J Neurol. 2012;19(1):155-62.

4. Committee on Facilitating Interdisciplinary Research, Committee on Science, Engineering, and Public Policy (2004). Facilitating interdisciplinary research. National Academies. Washington: National Academy Press, p. 2.

5. Wang X. A new vision of definition, commentary, and understanding in clinical and translational medicine. Clin Translat Med 2012;1:5.

6. Rubio DM, Schoenbaum EE, Lee LS, Schteingart DE, Marantz PR, Anderson KE, Platt LD, Baez A, Esposito K. Defining translational research: implications for training. Acad Med 2010;85(3):470-5

7. Hrncic D. Sleep, nutrition and physical exercise in brain hyperexcitability: translational viewpoint. Belgrade: Andrejevic Ed. 2015

8. Cohrs JR, Tyler M, Ghahramani P, Bidaut L, Higgins JP, Shahzad A. Translational Medicine definition by the European Society for Translational Medicine. New Horizon Translat Med 2015;2:86-88

9. Woolf $\mathrm{SH}$. The meaning of translational research and why it matters. JAMA. 2008;299(2):211-3. 